\title{
Focused Electrospray Deposition for Matrix-assisted Laser Desorption/Ionization Mass Spectrometry
}

\author{
Kyung Hwan Jeong, Jongcheol Seo, Hye-Joo Yoon, and Seung Koo Shin* \\ Bio-Nanotechnology Center, Department of Chemistry, Pohang University of Science and Technology, Pohang, Korea \\ *E-mail: skshin@postech.ac.kr \\ Received May 16, 2010, Accepted June 26, 2010
}

\begin{abstract}
Focused electrospray (FES) deposition method is presented for matrix-assisted laser desorption/ionization (MALDI) mass spectrometry. FES ion optics consists of two cylindrical focusing electrodes capped with a truncated conical electrode through which an electrospray emitter passes along the cylindrical axis. A spray of charged droplets is focused onto a sample well on a MALDI target plate under atmospheric pressure. The shape and size distributions of matrix crystals are visualized by scanning electron microscope and the mass spectra are obtained by time-of-flight mass spectrometry. Angiotensin II, bradykinin, and substance P are used as test samples, while $\alpha$-cyano-4-hydroxycinnamic acid and dihydroxybenzoic acid are employed as matrices. FES of a sample/matrix mixture produces fine crystal grains on a 1-3 mm spot and reproducibly yields the mass spectra with little shot-to-shot and spot-to-spot variations. Although FES greatly stabilizes the signals, the space charge due to matrix ions limits the detection sensitivity of peptides. To avoid the space charge problem, we adopted a dual FES/FES mode, which separately deposits matrix and sample by FES in sequence. The dual FES/FES mode reaches the detection sensitivity of 0.88 amol, enabling ultrasensitive detection of peptides by homogeneously depositing matrix and sample under atmospheric pressure.
\end{abstract}

Key Words: Focused electrospray, Atmospheric pressure ion focusing, Matrix-assisted laser desorption ionization

\section{Introduction}

Matrix-assisted laser desorption/ionization (MALDI) mass spectrometry (MS) is widely used for peptide identification and protein quantification. ${ }^{1}$ However, the detection sensitivity is greatly influenced by the method of sample preparation. ${ }^{2}$ One of the most commonly employed sample preparation methods is the so-called 'dried-droplet' (DD) deposition, which places a drop or droplets of a sample/matrix mixture on a MALDI target plate to dry in air. ${ }^{3}$ The slow drying of droplets produces sample/ matrix co-crystals which are heterodisperse in size, nonuniform in shape, ${ }^{4,5}$ and inhomogeneously distributed on the target with large clusters agglomerated around the periphery. ${ }^{4,5}$ As a result, the MALDI-MS signals show significant shot-to-shot and spotto-spot fluctuations, which limits the detection sensitivity. This detection sensitivity issue originating from the slow sample drying has been addressed by a number of approaches, such as fast solvent evaporation, ${ }^{6-9}$ matrix deposition by sublimation, ${ }^{10}$ and sample and matrix deposition by electrospray. ${ }^{11-16}$ The fast evaporation method first applies matrix dissolved in a volatile solvent to the target plate to form a thin matrix film and then loads a sample solution on top of the film. ${ }^{6,7}$ Although the detection sensitivity is greatly enhanced, the signal reproducibility is hardly improved because the multi-component samples are often segregated into nonhomogenous domains on the target plate. The matrix sublimation method applies matrix vapor sublimed at high temperature on the sample plate under the reduced pressure to deposit a fine, homogeneous film on the surface. ${ }^{10}$ However, a droplet of sample solution loaded on top of this film dissolves the matrix to yield sample/matrix crystals similar to those from DD deposition. On the other hand, the ES deposi- tion method ${ }^{14-16}$ applies a mist of charged droplets onto the target to form fine crystal grains evenly distributed across the spot. ${ }^{17-21}$ Consequently, the MALDI-MS signals are very reproducible with little shot-to-shot and spot-to-spot variations; however, the detection sensitivity is severely reduced because the electrospray disperses the sample over a wide area. ${ }^{22}$ If the diverging spray were collected onto a small well, the detection sensitivity would be greatly improved. ${ }^{15}$ To this end, we need to focus charged droplets onto a spot under atmospheric pressure. A number of electrostatic lens assemblies have been reported to date for collimating charged droplets from electrospray ionization (ESI) source ${ }^{23-27} \mathrm{An}$ ion funnel ${ }^{23}$ collimates ions under vacuum after passing through a sampling capillary. A venturi device increases the transmission efficiency of ions through a sampling orifice under atmospheric pressure. ${ }^{24,25}$ Recently, an electrostatic ion optics has been assembled to fabricate thin structured film on a solid substrate. ${ }^{26,27}$ Nevertheless, an atmospheric ion focusing device for ES deposition has rarely been applied to the MALDI sample preparation. Here, we report the focused electrospray (FES) deposition of sample on a MALDI target plate under atmospheric pressure.

We describe the basic design and operating conditions of FES, show the sample morphology, and present the advantages of FES on detection linearity and sensitivity. The sample morphology was characterized by scanning electron microscopy (SEM) and the MALDI mass spectra were taken with reflectron time-of-flight (TOF) MS. Both angiotensin II and bradykinin were used as test samples, and either $\alpha$-cyano-4-hydroxycinnamic acid (HCCA $)^{28}$ or dihydroxybenzoic acid (DHB) ${ }^{29}$ was employed as matrix. The performance of FES was evaluated by applying sample and matrix in two different modes: A single 
FES mode deposited a sample/matrix mixture by FES and a dual FES/FES mode separately deposited matrix and sample by FES. The dual FES/FES mode provided strong signals with enhanced detection sensitivity and linearity. However, there was a shortcoming: Electrospray-induced electrochemical oxidation of peptides. ${ }^{30-33}$ We characterized the effect of FES on electrochemical oxidation of substance $\mathrm{P}$ containing methionine.

\section{Experimental}

Reagents and materials. Angiotensin II (DRVYIHPF), bradykinin (RPPGFSPFR), substance P [(H)-RPKPQQFGLM$\left(\mathrm{NH}_{2}\right)$ ], $\alpha$-cyano-4-hydroxycinnamic acid (HCCA), dihydroxybenzoic acid (DHB), trifluoroacetic acid (TFA, sequencing grade), and formic acid (FA, sequencing grade) were purchased from Sigma-Aldrich (St. Louis, MO). Modified trypsin (sequencing grade) was obtained from Promega (Madison, WI). Acetonitrile (HPLC grade) was from Fisher Scientific (Fair Lawn, NJ). Water was purified with a Milli-Q Plus purification system (Millipore, Bedford, MA). All other chemicals were purchased from Sigma-Aldrich and used without further purification.

Matrix and peptide solutions. Matrix (HCCA or DHB) was dissolved in 1:1 acetonitrile/water $(\mathrm{v} / \mathrm{v})$ containing $0.1 \%$ TFA to a concentration of $5.0 \mu \mathrm{g} \mu \mathrm{L}^{-1}$. Standard peptide (angiotensin II, bradykinin, or substance P) was dissolved in 1:1 acetonitrile/ water containing $0.1 \%$ TFA to a concentration of $1.0 \mathrm{pmol} \mu \mathrm{L}^{-1}$.

Focused electrospray device. An FES setup is shown in Figure 1a, the geometry of ion optics in Figure 1b, and a threedimensional view of the potential grid and simulated ion trajectories in Figure 1c. The ion optics composed of a truncated, cone-shaped capping electrode and two cylindrical focusing electrodes was mounted on a Z-positioning stage using polyoxymethylene plastic holders. A multi-well MALDI target plate was placed on a motorized XY-positioning stage (Suruga Seiki KS211-200, Japan). An electrospray emitter passing through the capping electrode was located inside the middle cylindrical electrode. Electrospray was monitored through the slots $(1.0 \mathrm{~mm}$ wide $\times 10-15 \mathrm{~mm}$ long) made on the upper part of the middle electrode by using a CCD camera (JAI Corp. CV-S3200, Japan), a $200 \times$ optical zoom lens, and an illuminator (Edmund Optics, Stockeryale Imagelite Model 21).

The output from a syringe pump (Harvard Apparatus 11 pico plus, Holliston, MA) or a capillary LC (Agilent 1100, Palo Alto, CA) was delivered to one arm of a NanoTight Y connector (Upchurch Scientific, Oak Harbor, WA) through PEEK tubing (360- $\mu$ m o.d., 75- $\mu \mathrm{m}$ i.d., Upchurch Scientific). A matrix solution was delivered to another arm of $Y$ connector using a syringe pump. The foot of Y connector was linked to a conductive microfilter assembly (Upchurch Scientific m-534) through PEEK tubing and an electrospray tip (15 and 30- $\mu \mathrm{m}$ i.d., $50 \mathrm{~mm}$ long, Picotips, New Objective, Woburn, MA) was connected to the opposite end of filter assembly. The electrospray voltage was applied to the filter holder with a high-voltage power supply (Bertan Series 230, Hicksville, NY). The same voltage was applied to all three focusing electrodes with another highvoltage power supply (Bertan 205B-05R). The MALDI plate was held at ground. The ion current was measured by a Keithley
485 picoammeter (Cleveland, $\mathrm{OH}$ ).

Mass spectrometry and data analysis. The mass spectra were taken in reflection mode using a MALDI TOF mass spectrometer (Bruker Reflex III) equipped with a $337 \mathrm{~nm}$ nitrogen laser. Extraction, acceleration, and reflection voltages were set at $16.3,20.0$, and $23.0 \mathrm{kV}$, respectively. The m-over-z (Genomic Solutions) program was used for plotting and peak viewing, while the XMASS (Bruker Daltonics, Inc.) program was used for determining both the mass resolution and the signal-tonoise ratio $(\mathrm{S} / \mathrm{N})$.

\section{Results and Discussion}

Performance of focused electrospray. Geometries and potentials were first optimized by simulation using Simion 6.0 (Idaho National Engineering Laboratories, USA) under vacuum, as illustrated in Figure 1c, and then implemented on ion optics under atmospheric pressure by trial and error. A greater electrostatic gradient was required for the refraction of ions under atmospheric pressure than that under vacuum; because ion-neutral collisions dampen the ion kinetic energy. ${ }^{34}$ The optimized voltage applied in experiments was at least five times greater than that used in simulation. The focused spot size on the plate was visualized by forming white grains of HCCA matrix on the MALDI plate. ${ }^{35}$ As an example, a series of 1.3-mm white spots of HCCA matrix deposited on a 144-well MALDI plate is shown in Figure S1a in Supplementary Material (SM). Some

(a)
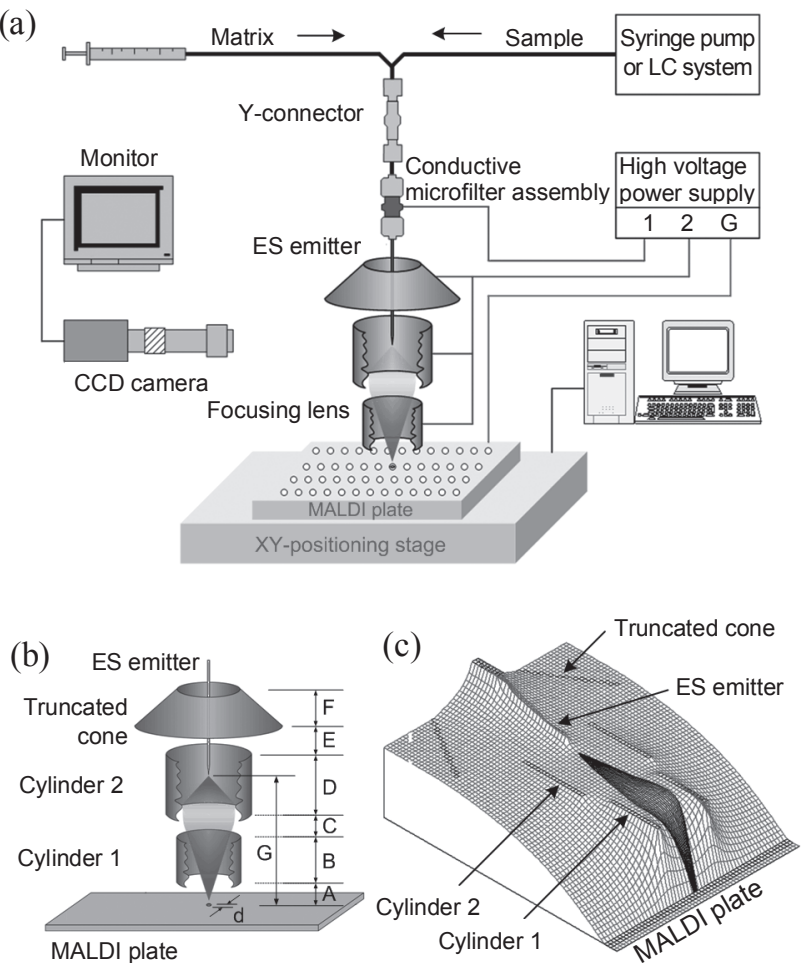

Figure 1. (a) Schematic of a focused electrospray (FES) setup for MALDI sample preparation; (b) geometry of ion optics used in FES deposition (see Table 1 for dimensions); (c) three-dimensional view of the grid potentials and ion trajectories from Simion simulation. The vertical axis represents the potential and the dark area shows the spread and focusing of ions. 
Table 1. Geometry of ion optics, ${ }^{a}$ focusing voltages and focused spot sizes.

\begin{tabular}{|c|c|c|c|c|c|c|c|}
\hline \multirow{2}{*}{$\mathrm{B}(\mathrm{mm})^{b}$} & \multirow{2}{*}{$\mathrm{C}(\mathrm{mm})$} & \multirow{2}{*}{$\mathrm{D}(\mathrm{mm})^{b}$} & \multirow{2}{*}{$\begin{array}{l}\text { tip size } \\
\text { (i.d.) }(\mu \mathrm{m})\end{array}$} & \multicolumn{2}{|c|}{ applied voltage $(\mathrm{kV})^{c}$} & \multirow{2}{*}{$\begin{array}{c}\text { tip-to-plate } \\
\text { distance } G(\mathrm{~mm})\end{array}$} & \multirow{2}{*}{$\begin{array}{c}\text { spot size } \\
\mathrm{d}(\mathrm{mm})\end{array}$} \\
\hline & & & & electrode & tip & & \\
\hline \multirow{3}{*}{15} & \multirow{6}{*}{5.0} & & & & & 13 & 6.0 \\
\hline & & 20 & & 4.0 & 7.5 & 18 & 5.5 \\
\hline & & & 15 & & & 23 & 4.5 \\
\hline \multirow{3}{*}{20} & & & 15 & & & 13 & 5.0 \\
\hline & & 20 & & 5.0 & 8.5 & 18 & 4.0 \\
\hline & & & & & & 23 & 3.0 \\
\hline 10 & 2.0 & 15 & 30 & $\begin{array}{l}4.0 \\
5.0\end{array}$ & $\begin{array}{l}7.0 \\
8.0\end{array}$ & 25 & $\begin{array}{l}2.5 \\
1.3\end{array}$ \\
\hline
\end{tabular}

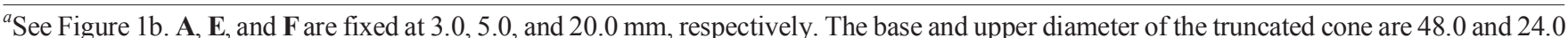
$\mathrm{mm}$, respectively. ${ }^{b}$ The length and diameter of cylindrical electrodes are the same. ${ }^{c}$ Relative to the MALDI target plate. Electrospray voltage is the voltage difference between the tip and focusing electrodes.

measured spot sizes are listed in Table 1 as a function of geometry (A-F), tip size, applied voltage, and tip-to-plate distance (G). The spot size (d) decreases as the tip moves away from the plate. At the same tip-to-plate distance, the spot size decreases with increasing voltage relative to the MALDI plate held at ground. For all MALDI mass analysis of standard peptides, we have used the ion focusing condition presenting a $1.3 \mathrm{~mm}$ spot size in Table 1 , where a matrix solution $\left(5 \mu \mathrm{g} \mu \mathrm{L}^{-1}\right.$ of HCCA) flows through a $30-\mu \mathrm{m}$ electrospray tip at the rate of $1.0 \mu \mathrm{L} \mathrm{min}{ }^{-1}$ with the tip holder held at a voltage $3-3.5 \mathrm{kV}$ higher than the focusing electrodes. As the flow rate increases, the spot size increases due to the space charge deteriorating the focusing conditions.

Matrix morphology. FES yields thin layers of fine crystals hardly visible to the naked eye (Figure S1c in SM), whereas DD results in thick, coarse crystal layers on the rim (Figure S1b in SM). The sample morphology was visualized by SEM. Images were obtained by spraying an aliquot $(1 \mu \mathrm{L})$ of a $1: 1$ mixture of $\mathrm{HCCA}\left(100 \mathrm{pmol} \mu \mathrm{L}^{-1}\right) /$ angiotensin II $\left(1 \mathrm{pmol} \mu \mathrm{L}^{-1}\right)$ or DHB $\left(8 \mathrm{nmol} \mu \mathrm{L}^{-1}\right) /$ bradykinin $\left(1 \mathrm{pmol} \mu \mathrm{L}^{-1}\right)$. With HCCA matrix, FES results in crystal grains of a few micrometers in size uniformly distributed on the spot, as shown in Figures 2a and S2a, similarly to the sample morphology obtained from a mist spray condition. ${ }^{20}$ Meanwhile, DD yields crystal grains of tens of micrometers in size inhomogeneously distributed on the spot, as displayed in Figures $2 \mathrm{~b}$ and S2b. With DHB matrix, FES produces thin layers of needle-shaped crystals of tens of micrometers in length (Figures $2 \mathrm{c}$ and S2c in SM), whereas DD yields thick crystal bundles of several hundred micrometers long (Figures 2d and S2d in SM). Apparently, the FES deposition gives rise to a more uniform spatial distribution of crystal grains with HCCA than with DHB.

Single FES deposition. A mixture of HCCA ( $5.0 \mu \mathrm{g}$ per spot $) /$ angiotensin II (5.0 fmol per spot) or DHB (5.0 $\mu \mathrm{g}$ per spot)/ bradykinin (1.0 fmol per spot) was deposited on a $1.3-\mathrm{mm}$ sample spot by single FES. The mass spectra of angiotensin II and bradykinin shown in Figure 3 were obtained by accumulating spectra for 5 laser shots on a single point (angiotensin II) or 20 laser shots randomly rastered over a sample spot (bradykinin). In the case of angiotensin II (Figures $3 a$ and $b$ ), the $S / N$ ratio varies from 190 to 227 for the $[\mathrm{M}+\mathrm{H}]^{+}$peak at $m / z 1046 \mathrm{Th}$ with the relative standard deviation (RSD) of 7.7\%. This RSD
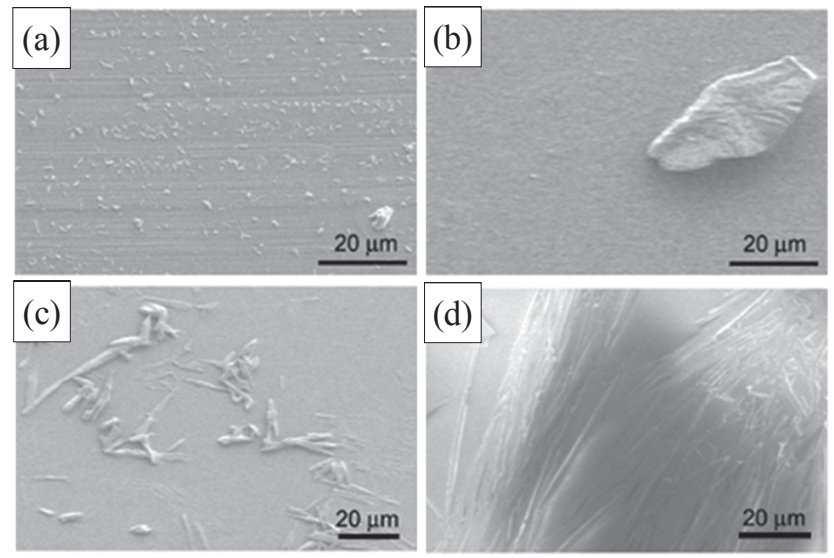

Figure 2. Scanning electron microscope (SEM) images of HCCA $\left(100 \mathrm{pmol} \mu \mathrm{L}^{-1}\right)$ plus angiotensin II $\left(1 \mathrm{pmol} \mu \mathrm{L}^{-1}\right)$ deposited by (a) focused electrospray and (b) dried droplet; SEM images of DHB ( 8 nmol $\mu \mathrm{L}^{-1}$ ) plus bradykinin (1 pmol $\left.\mu \mathrm{L}^{-1}\right)$ deposited by (c) focused electrospray and (d) dried droplet.

value is about eight times less than a typical RSD value of $60 \%$ from DD deposition of HCCA/angiotensin II. ${ }^{36}$ With bradykinin (Figures $3 \mathrm{c}$ and $\mathrm{d}$ ), the $\mathrm{S} / \mathrm{N}$ ratio varies from 28 to 42 for the $[\mathrm{M}+\mathrm{H}]^{+}$peak at $\mathrm{m} / \mathrm{z} 1060 \mathrm{Th}$ with an RSD value of $17 \%$, which is comparable to that of $22 \%$ from DD deposition of DHB/ angiotensin II. ${ }^{36} \mathrm{FES}$ greatly improves the signal reproducibility with HCCA matrix, thus employing HCCA for all of the subsequent experiments. However, single FES reaches the detection limit of $0.1 \mathrm{fmol}$ per spot due to the space charge saturated by matrix ions. This space charge also deteriorates the focusing condition.

Dual FES/FES deposition. To circumvent the space charge problem, we separately deposited matrix and sample on the target plate, as suggested by McLeod et al. ${ }^{15}$ Under the present FES condition, 2-3 $\mu \mathrm{m}$ long HCCA crystal grains were evenly distributed on the $1.3-\mathrm{mm}$ spot and the sample solution containing angiotensin II was applied over matrix grains by FES. The sample morphology by dual FES/FES mode was almost identical to that by single FES, as shown in Figure S3 (SM), because solvent evaporated fast before charged droplets arrived at the target plate. The mass spectra were obtained as a function of both the amount of peptide loaded on the spot and the number 

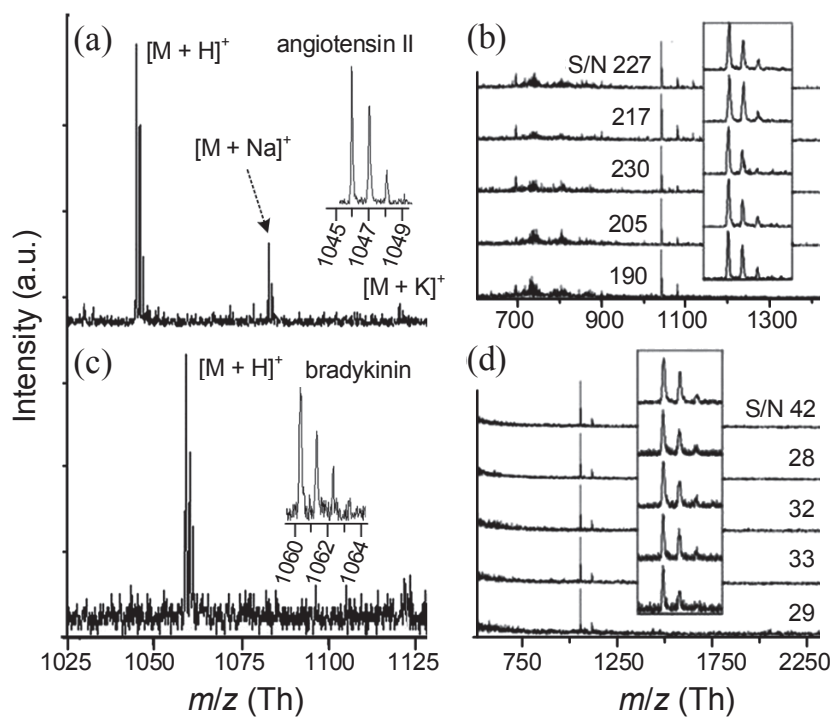

Figure 3. MALDI mass spectra of (a) angiotensin II ( 5 fmol per spot) plus HCCA (5.0 $\mu \mathrm{g}$ per spot) and (c) bradykinin (1.0 fmol per spot) plus DHB (5.0 $\mu \mathrm{g}$ per spot) deposited by single FES. The isotope patterns of [angiotensin $\mathrm{II}+\mathrm{H}]^{+}$and [bradykinin $\left.+\mathrm{H}\right]^{+}$are also shown; Variation of the signal-to-noise $(\mathrm{S} / \mathrm{N})$ ratio of $(\mathrm{b})$ angiotensin II and (d) bradykinin. The mass spectra of angiotensin II $(a, b)$ and bradykinin (c, d) are accumulated for 5 and 20 laser shots, respectively.

of laser shot. The amount of peptide was serially diluted by 10 -fold from $88 \mathrm{fmol}$ to $0.88 \mathrm{amol}$ with the amount of matrix kept at $5.0 \mu \mathrm{g}$ per spot. The mass spectra shown in Figure 4 were obtained by accumulating for 100 laser shots randomly rastered over the sample spot. The $[\mathrm{M}+\mathrm{H}]^{+}$peak of angiotensin II appears strong over a wide dynamic range of sample concentration from $88 \mathrm{fmol}$ to $0.88 \mathrm{amol}$ per spot, presenting the $\mathrm{S} / \mathrm{N}$ ratio from 698 at $88 \mathrm{fmol}$ to 22 at 0.88 amol.

To further examine the detection sensitivity and linearity, we obtained the mass spectra by varying the number of laser shot from 100 to 500 in the concentration range of 880-0.88 amol per spot. The intensity of the $[\mathrm{M}+\mathrm{H}]^{+}$peak is plotted as a function of laser shot in Figure 5. The peak intensity increases linearly with increasing number of laser shot, even in the case of 0.88 amol of sample concentration (Figure 5a), which indicates that the detection limit is close to $0.88 \mathrm{amol}$. However, the ascending slope (Figure 5a) declines as the sample concentration decreases, suggesting that the detection sensitivity is not linear. Further, we checked the detection linearity by converting the accumulated intensity (Figure 5a) to the average intensity per laser shot (Figure 5b). The average single-shot intensity increases with increasing sample concentration on a logarithmic scale, indicating that the average intensity is also far from being linear. Although the dual FES/FES deposition greatly improve the signal reproducibility and significantly lowers the detection limit, FES alone is not suffice for absolute quantification of peptides.

Oxidation of peptide by electrospray. Lastly, we observed the oxidation of substance P deposited by FES, as shown in Figure 6. To confirm this oxidation, we first deposited HCCA (5.0 $\mu \mathrm{g}$ per spot) on the target plate by FES and then loaded substance $\mathrm{P}(1.0 \mathrm{pmol}$ per spot) by either DD or FES. With

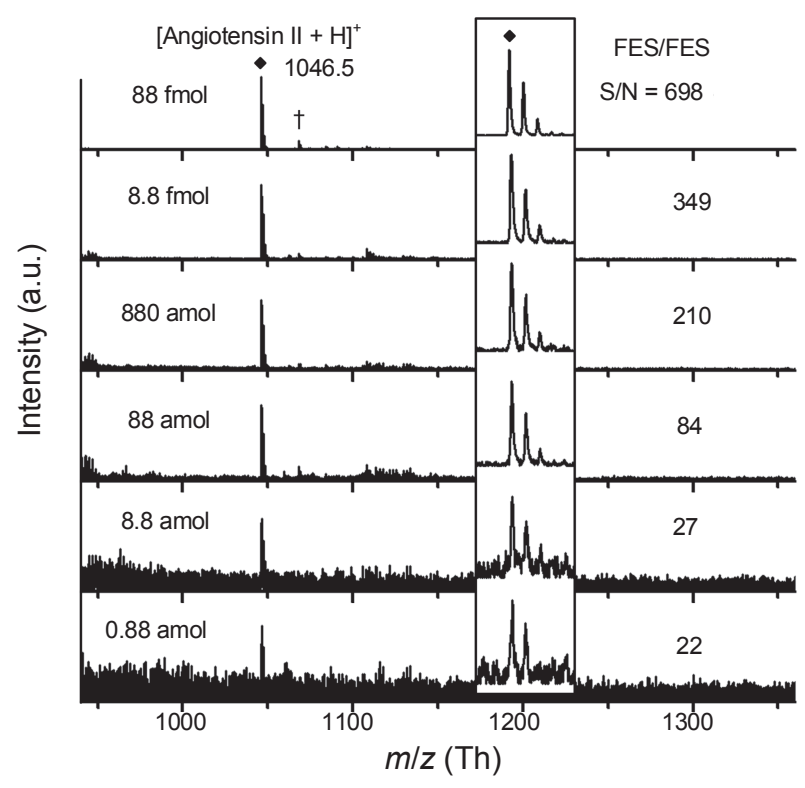

Figure 4. MALDI mass spectra of angiotensin II as a function of the amount of sample deposited by dual FES/FES. $[\mathrm{M}+\mathrm{H}]^{+}$is marked by diamond. $[\mathrm{M}+\mathrm{Na}]^{+}$is denoted by dagger. The isotope patterns of $[\mathrm{M}+$ $\mathrm{H}]^{+}$are also displayed. The mass spectra are obtained by accumulating for 100 laser shots by randomly moving the target point after every three laser shots.
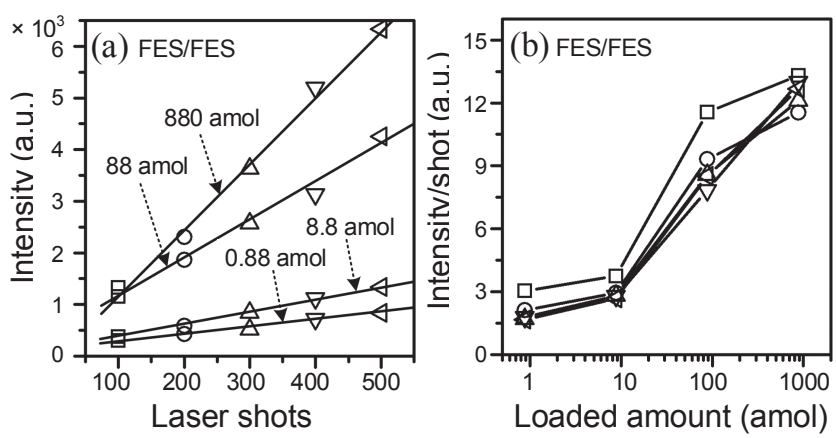

Figure 5. (a) Intensity of the angiotensin II $[\mathrm{M}+\mathrm{H}]^{+}$peak as a function of the number of laser shot in various sample concentrations from 880 to 0.88 amol under dual FES/FES mode; (b) the average intensity per laser shot as a function of sample concentration on a logarithmic scale under dual FES/FES mode.

DD deposition of peptide involving no electrochemical oxidation (Figure 6a), nearly $80 \%$ of substance $\mathrm{P}(\mathrm{m} / \mathrm{z} 1347.7 \mathrm{Th})$ is found to be intact. Notably, with FES deposition at high voltage (Figure 6b), no substance $P$ remains intact and all peptides are oxidized, manifesting the electrochemical oxidation of methionine by electrospray. ${ }^{30}$ In addition to singly- and doublyoxidized peaks at $\mathrm{m} / \mathrm{z} 1363.7$ and $1379.7 \mathrm{Th}$, respectively, an unknown peak at $\mathrm{m} / \mathrm{z} 1308.5 \mathrm{Th}$ appears strong. It is well known that the thioether side chain of methionine is oxidized, first to sulfoxide and subsequently to sulfone, ${ }^{31}$ as depicted in Scheme 1.<smiles>CC(C)CCCCSCCC(C)C</smiles>

Scheme 1. Sequential oxidation of methonine side chain 


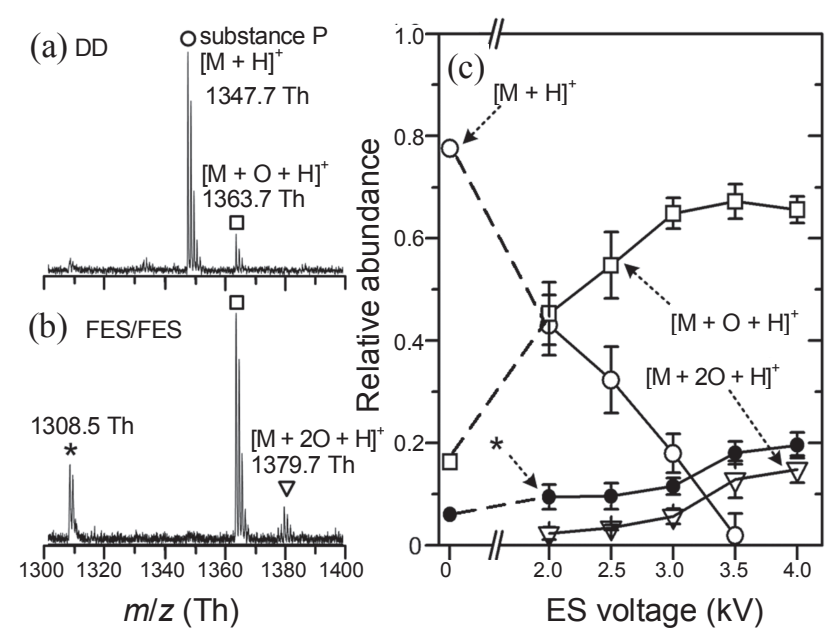

Figure 6. MALDI mass spectra of substance $\mathrm{P}(1 \mathrm{pmol}$ per spot) plus HCCA (5.0 $\mu$ g per spot) deposited by (a) dried-droplet (DD) and (b) dual FES/FES (electrospray voltage of $4.5 \mathrm{kV}$ ). The mass spectra are obtained by accumulating for 100 laser shots. (c) Relative abundances of intact $\left([\mathrm{M}+\mathrm{H}]^{+}\right)$, singly- $\left([\mathrm{M}+\mathrm{O}+\mathrm{H}]^{+}\right)$and doubly-oxidized $([\mathrm{M}+$ $2 \mathrm{O}+\mathrm{H}]^{+}$) subtance $\mathrm{P}$ as well as the unknown peak (denoted by asterisk) at $\mathrm{m} / \mathrm{z} 1308.7 \mathrm{Th}$ as a function of electrospray voltage.

Thus, substance $\mathrm{P}$ containing methionine at the $\mathrm{C}$-terminus undergoes electrochemical oxidation in solution while flowing through a $50 \mathrm{~mm}$ long electrospray emitter. ${ }^{32}$ To further examine the effect of electrospray voltage on the degree of methionine oxidation, we acquired the mass spectra of substance $\mathrm{P}$ as a function of electrospray voltage, the difference between the electrospray emitter holder and the focusing electrode. Relative abundances of $[\mathrm{M}+\mathrm{H}]^{+}$at $1347.4 \mathrm{Th},[\mathrm{M}+\mathrm{O}+\mathrm{H}]^{+}$at 1363.7 $\mathrm{Th},[\mathrm{M}+2 \mathrm{O}+\mathrm{H}]^{+}$at $1379.7 \mathrm{Th}$, and the unknown peak at 1308.5 Th are plotted in Figure 6c. As the relative abundance of $[\mathrm{M}+\mathrm{H}]^{+}$decreases with increasing electrospray voltage from 2.0 to $4.0 \mathrm{kV}$, that of $[\mathrm{M}+\mathrm{O}+\mathrm{H}]^{+}$increases up to $3.5 \mathrm{kV}$ and then declines, while those of $[\mathrm{M}+2 \mathrm{O}+\mathrm{H}]^{+}$and the peak at $\mathrm{m} / \mathrm{z} 1308.5 \mathrm{Th}$ increase simultaneously. This result suggests that both $[\mathrm{M}+2 \mathrm{O}+\mathrm{H}]^{+}$and $\mathrm{m} / \mathrm{z} 1308.5$ Th peaks derive from the same precursor $[\mathrm{M}+\mathrm{O}+\mathrm{H}]^{+}$. The peak at $m / z 1308.5 \mathrm{Th}$ is tentatively assigned to loss of $\mathrm{C}_{3} \mathrm{H}_{5} \mathrm{NO}$ from $[\mathrm{M}+2 \mathrm{O}+\mathrm{H}]^{+}$. Apparently, the electrospray-induced electrochemical oxidation of amino acid side chains is the shortcoming of FES deposition.

\section{Conclusions}

The focused electrospray deposition results in fine crystal grains with HCCA matrix and needle-shaped crystals with DHB matrix, thus providing a more homogeneous sample distribution with the former matrix. With HCCA, the focused electrospray produces the sample morphology similar to that obtained from a mist spray. The focused electrospray deposition significantly improves the signal reproducibility by reducing both shot-toshot and spot-to-spot fluctuations and greatly enhances the detection sensitivity by collimating charged droplets on a sample spot. Although the electrochemical oxidation of peptides could occur in solution during electrospray at high voltage, the dual FES/FES deposition achieves the detection sensitivity at the sub-attomole level.
Acknowledgments. We thank W. Min for the help in setting up the FES device for the electrochemical oxidation of substance P. We are grateful for the support from the Functional Proteomics Center (Grant FPR08A1-040) and the POSTECH Biotech Center.

Supplementary Material. Spot images of a 144-well MALDI plate visualized after focused electrospray deposition of HCCA matrix; microscope images of a 3-mm (diameter) spot of DHB matrix deposited on a 384-well MALDI plate; scanning electron microscopy images of sample/matrix prepared by single FES, dried droplet, and dual FES/FES deposition methods.

\section{References}

1. Moyer, S. C.; Cotter, R. J. Anal. Chem. 2002, 74, 468 A-476 A.

2. Cohen, S. L.; Chait, B. T. Anal. Chem. 1996, 68, 31-37.

3. Karas, M.; Hillenkamp, F. Anal. Chem. 1988, 60, 2299-2301.

4. Dai, Y.; Whittal, R. M.; Li, L. Anal. Chem. 1996, 68, 2494-2500.

5. Garden, R. W.; Sweedler, J. V. Anal. Chem. 2000, 72, 30-36.

6. Vorm, O.; Roepstorff, P.; Mann, M. Anal. Chem. 1994, 66, 32813287.

7. Vorm, O.; Mann, M. J. Am. Soc. Mass Spectrom. 1994, 5, 955-958.

8. Nicola, A. J.; Gusev, A. I.; Proctor, A.; Jackson, E. K.; Hercules, D. M. Rapid Commun. Mass Spectrom. 1995, 9, 1164-1171.

9. Dai, Y.; Whittal, R. M.; Li, L. Anal. Chem. 1999, 71, 1087-1091.

10. Hankin, J. A.; Barkley, R. M.; Murphy, R. C. J. Am. Soc. Mass Spectrom. 2007, 18, 1646-1652.

11. McNeal, C. J.; Macfarlane, R. D.; Thurston, E. L. Anal. Chem. 1979, 51, 2036-2039.

12. Whitehouse, C. M.; Dreyer, R. N.; Yamashita, M.; Fenn, J. B. Anal. Chem. 1985, 57, 675-679.

13. Roepstorff, P.; Nielsen, P. F.; Sundqvist, B. U. R.; Håkansson, P.; Jonsson, G. Int. J. Mass Spectrom. Ion Processes 1987, 78, 229-236.

14. Axelsson, J.; Hoberg, A.-M.; Waterson, C.; Myatt, P.; Shield, G. L.; Varney, J.; Haddleton, D. M.; Derrick, P. J. Rapid Commun. Mass Spectrom. 1997, 11, 209-213.

15. McLeod, G. S; Axelsson, J.; Self, R.; Derrick, P. J. Rapid Commun. Mass Spectrom. 1997, 11, 214-218.

16. Hensel, R. R.; King, R. C.; Owens, K. G. Rapid Commun. Mass Spectrom. 1997, 11, 1785-1793.

17. Hanton, S. D.; Clark, P. A. C.; Owens, K. G. J. Am. Soc. Mass Spectrom. 1999, 10, 104-111.

18. Go, E. P.; Shen, S.; Harris, K.; Siuzdak, G. Anal. Chem. 2003, 75, 5475-5479.

19. Hanton, S. D.; Hyder, I. Z.; Stets, J. R.; Owens, K. G.; Blair, W. R.; Guttman, C. M.; Giuseppetti, A. A. J. Am. Soc. Mass Spectrom. 2004, 15, 168-179.

20. Wei, H.; Nolkrantz, K.; Powell, D. H.; Woods, J. H.; Ko, M.-C.; Kennedy, R. T. Rapid Commun. Mass Spectrom. 2004, 18, 1193 1200.

21. Wang, Y.-X.; Zhou, Y.; Balgley, B. M.; Cooper, J. W.; Lee, C. S.; DeVoe, D. L. Electrophoresis 2005, 26, 3631-3640.

22. Thompson, J. W.; Eschelbach, J. W.; Wilburn, R. T.; Jorgenson, J. W. J. Am. Soc. Mass Spectrom. 2005, 16, 312-323.

23. Shaffer, S. A.; Prior, D. C.; Anderson, G. A.; Udseth, H. R.; Smith, R. D. Anal. Chem. 1998, 70, 4111-4119.

24. Morozov, V. N.; Morozova, T. Y. Anal. Chem. 1999, 71, 31103117.

25. Schneider, B. B.; Douglas, D. J.; Chen, D. D. Y. Rapid Commun. Mass Spectrom. 2001, 15, 2168-2175.

26. Zhou, L.; Yue, B.; Dearden, D. V.; Lee, E. D.; Rockwood, A. L.; Lee, M. L. Anal. Chem. 2003, 75, 5978-5983.

27. Saf, R.; Goriup, M.; Steindl, T.; Hamedinger, T. E.; Sandholzer, D.; Hayn, G. Nat. Mater. 2004, 3, 323-329.

28. Beavis, R. C.; Chaudhary, T.; Chait, B. T. Organic Mass Spectrom. 
1992, 27, 156-158.

29. Strupat, K.; Karas, M.; Hillenkamp, F. Int. J. Mass Spectrom. Ion. Proc. 1991, 111, 89-102.

30. Guan, Z.; Yates, N. A.; Bakhtiar, R. J. Am. Soc. Mass Spectrom. 2003, 14, 605-613.

31. Kotiaho, T.; Eberlin, M. N.; Vainiotalo, P.; Kostiainen, R. J. Am. Soc. Mass Spectrom. 2000, 11, 526-535.

32. de la Mora, J. F.; Van Berkel, G. J.; Enke, C. G.; Cole, R. B.; Mar-
tinez-Sanchez, M.; Fenn, J. B. J. Mass Spectrom. 2000, 35, 939952.

33. Xu, G.; Chance, M. R. Chem. Rev. 2007, 107, 3514-3543.

34. Dahl, D. A.; McJunkin, T. R.; Scott, J. R. Int. J. Mass Spectrom. 2007, 266, 156-165.

35. Bogan, M. J.; Agnes, G. R. Rapid Commun. Mass Spectrom. 2004, $18,2673-2681$

36. Mank, M.; Stahl, B.; Boehm, G. Anal. Chem. 2004, 76, 2938-2950. 